\title{
Scaler Device
}

National Cancer Institute

\section{Source}

National Cancer Institute. Scaler Device. NCI Thesaurus. Code C50157.

An electronic counter device designed to output a pulse in response to a set number of input pulses. Also refers to a physical device designed to scrape hardened material from the surface of a tooth. 